\title{
The Epidemiology of Unintentional and Violence-Related Injury Morbidity and Mortality among Children and Adolescents in the United States
}

\author{
Michael F. Ballesteros ${ }^{1, *}$, Dionne D. Williams ${ }^{1}$, Karin A. Mack ${ }^{1}$, Thomas R. Simon ${ }^{2}$ and \\ David A. Sleet ${ }^{3,4}$ \\ 1 Division of Analysis, Research and Practice Integration, National Center for Injury Prevention and Control, \\ Centers for Disease Control and Prevention, Atlanta, GA 30341, USA; duw0@cdc.gov (D.D.W.); \\ kim9@cdc.gov (K.A.M.) \\ 2 Division of Violence Prevention, National Center for Injury Prevention and Control, Centers for Disease \\ Control and Prevention, Atlanta, GA 30341, USA; tgs9@cdc.gov \\ 3 The Bizzell Group, LLC, Lanham, MD 20706, USA; davidasleet@gmail.com \\ 4 Division of Unintentional Injury Prevention, National Center for Injury Prevention and Control, \\ Centers for Disease Control and Prevention, Atlanta, GA 30341, USA \\ * Correspondence: zzb0@cdc.gov
}

Received: 6 February 2018; Accepted: 21 March 2018; Published: 28 March 2018

\begin{abstract}
Injuries and violence among young people have a substantial emotional, physical, and economic toll on society. Understanding the epidemiology of this public health problem can guide prevention efforts, help identify and reduce risk factors, and promote protective factors. We examined fatal and nonfatal unintentional injuries, injuries intentionally inflicted by other (i.e., assaults and homicides) among children ages 0-19, and intentionally self-inflicted injuries (i.e., self-harm and suicides) among children ages 10-19. We accessed deaths (1999-2015) and visits to emergency departments (2001-2015) for these age groups through the Centers for Disease Control and Prevention's (CDC) Web-based Injury Statistics Query and Reporting System (WISQARS), and examined trends and differences by age, sex, race/ethnicity, rural/urban status, and injury mechanism. Almost 13,000 children and adolescents age 0-19 years died in 2015 from injury and violence compared to over 17,000 in 1999. While the overall number of deaths has decreased over time, there were increases in death rates among certain age groups for some categories of unintentional injury and for suicides. The leading causes of injury varied by age group. Our results indicate that efforts to reduce injuries to children and adolescents should consider cause, intent, age, sex, race, and regional factors to assure that prevention resources are directed at those at greatest risk.
\end{abstract}

Keywords: injury; homicide; suicide; children; adolescents; epidemiology

\section{Introduction}

Injuries and violence among young people continue to have a substantial emotional, physical, and economic toll on society. On average, a child dies every hour in the United States from an injury or violent act, and over $30 \%$ of all deaths among children age 1-19 years are from injuries or violence $[1,2]$. Another 22,200 children on average are seen every day in U.S. emergency departments (ED) seeking treatment for nonfatal injuries [1,2]. Injuries can be intentional, such as from an assault, homicide, or suicide/self-harm, or they can be unintentional, such as from motor vehicle crashes, drowning, poisoning, fires/burns, falls, or suffocation. Injuries can have lasting consequences and result in a substantial economic burden on society. Each year, injuries to U.S. children 0-19 years of age result in an estimated $\$ 94$ billion in lifetime medical and work-loss costs [1]. 
Understanding epidemiology is critical to injury control as it can provide a picture of the public health and economic burdens that can guide prevention efforts, help identify and reduce risk factors, and increase protective factors. The purpose of this study is to use recent U.S. data to examine in detail the epidemiology of injuries among children ages 0-19 years by age, sex, race/ethnicity, rural/urban status, and injury mechanism. We specifically focus on trends and differences by injury intent and age group for both fatal and non-fatal injury rates.

\section{Methods}

We examined data on fatal and non-fatal injuries among children and teens aged 0-19 years using two large data systems. All data were accessed using the Centers for Disease Control and Prevention's (CDC) Web-based Injury Statistics Query and Reporting System (WISQARS), which is a free, interactive, online database that provides information on fatal and nonfatal injuries and cost of injuries from a variety of trusted sources [1,3]. Data are publically available and provide no personal identifiable information. Institutional Review Board (IRB) approval was not needed for this study.

\subsection{Mortality}

Data on deaths due to injuries and violence came from 1999-2015 WISQARS fatal reports, which uses the National Vital Statistics System (NVSS). NVSS receives death certificate data from 50 states and the District of Columbia. Injury deaths were defined as those with an underlying cause of death classified by external cause of injury codes (International Classification of Diseases, 10th Revision ICD-10; https:/ / www.cdc.gov/injury/wisqars/fatal_help/data_sources.html). Unintentional injury ICD-10 codes used were V01-X59 or Y85-Y86. Homicide and legal intervention (hereafter, referred to as homicides) deaths included ICD-10 codes X85-Y09, Y87.1, Y35, Y89.0, or *U01-*U02 (terrorism); and suicide deaths included codes X60-X84, Y87.0, or *U03 (terrorism). Unintentional injury did not include iatrogenic injuries (Y40-Y84) and intentional injury did not include operations of war (Y36). The number of suicide deaths and rates were calculated only for youth 10 years of age and older. Children aged $<10$ years were excluded because suicidal intent is often not attributed to young children. These detailed codes for injury deaths are expressed in mechanism (cause) groupings in WISQARS (e.g., motor vehicle traffic (MV) occupants, poisonings, fires/burns, falls, and suffocations) using the external cause-of-injury mortality matrix [4]. Deaths for individuals coded as unspecified MV traffic road users were included with MV occupant deaths [5]. While the mechanism of homicide and suicide deaths (e.g., firearm, poisoning) can be determined on WISQARS, they are combined in this analysis because of low counts in some data cells.

Metropolitan ('metro') or non-metropolitan ('non-metro') categories were assigned to deaths based on the National Center for Health Statistics' (NCHS) six-level county-based urbanization classifications for 2013 [6]. The 'metro' classification was defined by collapsing urbanization codes for large central metro, large fringe metro, medium metro, and small metro counties; and the 'non-metro' classification included micropolitan and non-core counties. This paper highlights results from the collapsed two-level metro/non-metro classification based on the 2013 urbanization classification scheme that was applied to the 1999-2015 data. We examined death rates by age group, sex, race/ethnicity, injury mechanism, metro/non-metro status, state, and year.

\subsection{Morbidity}

Data on individuals treated in U.S. EDs for non-fatal injuries came from the 2001-2015 National Electronic Injury Surveillance System-All Injury Program (NEISS-AIP). The NEISS is an ongoing surveillance system that monitors consumer product-related injuries treated in U.S. hospital EDs. The U.S. Consumer Product Safety Commission maintains and operates NEISS, which currently includes 100 hospital emergency departments (ED) that represent a stratified probability sample of all U.S. and U.S. territory hospitals that have at least six beds and provide 24-hour emergency services. NEISS-AIP is a subsample of 66 of the 100 NEISS hospitals. NEISS-AIP tracks all injuries seen in 
EDs, whether or not they are associated with consumer products. Data from these cases are weighted by the inverse of the probability of selection to provide national estimates. Non-fatal injuries were examined by manner (unintentional, intentionally inflicted by another-including sexual assault and legal intervention — hereafter 'assault' — and self-harm), age group and mechanism. All definitions of causes are provided on the WISQARS website [1], but note that "struck by/against or crushed" is defined as an injury resulting from being struck by (hit) or crushed by a human, animal, or inanimate object or force other than a vehicle or machinery.

Fatal and non-fatal rates were calculated using the U.S. Census population totals with bridged race categories [7].

\section{Results}

In 2015, there were 12,977 injury deaths among individuals 0-19 years of age, with an overall crude death rate of 16.2 per 100,000 population. In contrast, there were 17,632 injury deaths in 1999. In 2015, $61 \%$ of deaths were unintentional, $20 \%$ were homicides, and $19 \%$ were suicides. Males accounted for $69 \%$ of the deaths and had an overall crude death rate over two times greater than females (21.3 versus 10.0). Infants (less than one year old) (39.1) and youth 15-19 (36.0) years old had the highest injury crude death rates (Table 1).

Table 1. Fatal and non-fatal injuries among youth aged 0-19 years by intent, sex, and age group, National Vital Statistics System and National Electronic Injury Surveillance System-All Injury Program, United States, 2015.

\begin{tabular}{|c|c|c|c|c|c|c|c|}
\hline & \multicolumn{3}{|c|}{ Deaths } & \multicolumn{4}{|c|}{ Non-Fatal } \\
\hline & Number & $\%$ & Rate & Number & $95 \% \mathrm{CI}$ & $\%$ & Rate \\
\hline \multicolumn{8}{|l|}{ Intent } \\
\hline Unintentional & 7963 & $61.4 \%$ & 9.7 & $7,680,704$ & $6,413,696-8,97,712$ & $94.7 \%$ & 9352.4 \\
\hline Homicide * / Assault * & 2544 & $19.6 \%$ & 3.1 & 305,183 & $223,016-387,349$ & $3.8 \%$ & 371.6 \\
\hline Suicide/Self Harm & 2470 & $19.0 \%$ & 3.0 & 129,645 & $105,176-155,977$ & $1.6 \%$ & 157.9 \\
\hline \multicolumn{8}{|l|}{ Sex } \\
\hline Male & 8951 & $69.0 \%$ & 21.3 & $4,610,917$ & $3,861,281-5,362,064$ & $56.9 \%$ & $10,990.2$ \\
\hline Female & 4026 & $31.0 \%$ & 10.0 & $3,504,615$ & $2,942,641-4,066,941$ & $43.2 \%$ & 8724.3 \\
\hline \multicolumn{8}{|l|}{ Age Group } \\
\hline$<1$ & 1554 & $12.0 \%$ & 39.1 & 223,797 & $167,767-279,828$ & $2.8 \%$ & 5625.8 \\
\hline $1-4$ & 1604 & $12.4 \%$ & 10.1 & $1,783,392$ & $1,419,085-2,147,715$ & $22.0 \%$ & $11,195.7$ \\
\hline $5-9$ & 895 & $6.9 \%$ & 4.4 & $1,620,968$ & $1,345,861-1,897,923$ & $20.0 \%$ & 7912.1 \\
\hline 10-14 & 1330 & $10.2 \%$ & 6.4 & $1,964,533$ & $1,665,919-2,263,147$ & $24.2 \%$ & 9526.2 \\
\hline $15-19$ & 7594 & $58.5 \%$ & 36.0 & $2,522,842$ & $2,145,646-2,900,036$ & $31.1 \%$ & $11,951.6$ \\
\hline Total & 12,977 & $100.0 \%$ & 16.2 & $8,115,532$ & $6,807,635-9,425,292$ & $100.0 \%$ & 9881.8 \\
\hline
\end{tabular}

Additionally, in 2015, we estimate there were over 8.1 million children 0-19 years of age treated in a U.S. ED for a non-fatal injury (versus over 10.3 million in 1999), with $95 \%$ of these visits for unintentional injuries compared with $4 \%$ for assaults and $2 \%$ for self-harm injuries. The highest estimated non-fatal injury rates were among those ages $1-4$ years (11,196 per 100,000 population) and ages 15-19 years (11,952 per 100,000). Estimated rates of ED visits (9352 per 100,000) for unintentional injury were almost 20 times higher than for intentional injury (371 per 100,000). Males accounted for $57 \%$ of the non-fatally injured patients (Table 1 ). 


\subsection{Leading Causes of Injury Mortality and Morbidity}

\subsubsection{Mortality}

For infants under the age of one, unintentional suffocation was the leading cause of injury death, with over four times the number of deaths as the second leading cause of injury death, homicide (Table 2). Unintentional drowning was the leading cause of injury death for children 1-4 years old, and motor vehicle traffic death was the leading cause of injury death for children 5 years and older. Homicides were either the second or the third leading cause of injury death in all age groups, while suicides ranked second for those 10-14 and 15-19 years old. For all age groups, the leading injury mechanisms for homicide were firearm, cut/pierce, and suffocation; and the leading mechanisms for suicide were suffocation, firearm, and poisoning (data not shown).

\subsubsection{Morbidity}

Among children younger than 15 years, unintentional falls were the leading cause of ED visits for injury (Table 3). Unintentionally being struck by/against was the leading cause of ED visits for those 15-19 years, and the second leading cause for all other age groups. We estimate almost 250,000 youth 10-19 years of age were seen in an ED for an assault (the most common injury mechanism being struck by/against, sexual assault, cut/pierce, and firearm); almost 130,000 in the same age group were seen for self-harm injuries (poisoning, cut/pierce, and other specified mechanisms). 
Table 2. Leading causes of injury and violence related deaths among youth aged 0-19 years, National Vital Statistics System, United States, 2015.

\begin{tabular}{|c|c|c|c|c|c|c|c|c|c|}
\hline \multicolumn{2}{|c|}{$<1$ Years } & \multicolumn{2}{|c|}{ 1-4 Years } & \multicolumn{2}{|c|}{ 5-9 Years } & \multicolumn{2}{|c|}{ 10-14 Years } & \multicolumn{2}{|c|}{ 15-19 Years } \\
\hline & Number & & Number & & Number & & Number & & Number \\
\hline Unintentional & $\underline{1291}$ & Unintentional & $\underline{1235}$ & Unintentional & 755 & Unintentional & $\underline{763}$ & Unintentional & $\underline{3919}$ \\
\hline Suffocation & 1125 & Drowning & 390 & MV Traffic & 351 & MV Traffic & $\overline{412}$ & MV Traffic & 2535 \\
\hline MV Traffic & 64 & MV Traffic & 332 & Drowning & 129 & Drowning & 87 & Poisoning & 676 \\
\hline Drowning & 30 & Suffocation & 131 & Fire/Burn & 72 & Other Land Transp. & 51 & Drowning & 225 \\
\hline Fire/Burn & 22 & Fire/Burn & 100 & Other Land Transp. & 32 & Fire/Burn & 41 & Other Land Transp. & 85 \\
\hline Nat/Environment & 12 & Pedestrian & 75 & Suffocation & 31 & Poisoning & 36 & Fall & 64 \\
\hline Poisoning & 9 & Fall & 30 & Nat/Environment & 24 & Suffocation & 26 & Firearm & 52 \\
\hline Other Land Transp. & 5 & Poisoning & 29 & Pedestrian & 20 & Firearm & 15 & Pedestrian & 51 \\
\hline Struck by/Against & 5 & Struck by/Against & 27 & Poisoning & 17 & Other Transp. & 14 & Suffocation & 32 \\
\hline Fall & 4 & Firearm & 25 & Struck by / Against & 17 & Fall & 13 & Fire/Burn & 26 \\
\hline Pedestrian & 2 & Nat/Environment & 25 & Fall & 12 & Pedestrian & 11 & Other Transp. & 22 \\
\hline Homicides * & 263 & Homicides * & 369 & Homicides * & 140 & Homicides * & 158 & Homicides * & 1614 \\
\hline Suffocation & $\frac{24}{24}$ & Firearm & 50 & Firearm & $\frac{76}{69}$ & Firearm & $\frac{121}{121}$ & Firearm & 1422 \\
\hline Drowning & 8 & Suffocation & 31 & Cut/Pierce & 11 & Cut/Pierce & 8 & Cut/Pierce & 99 \\
\hline \multirow[t]{5}{*}{ Firearm } & 8 & Drowning & 14 & Suffocation & 10 & Fire/Burn & 7 & Suffocation & 14 \\
\hline & & & & & & Suicides & 409 & Suicides & 2061 \\
\hline & & & & & & Suffocation & $\overline{234}$ & $\overline{\text { Firearm }}$ & 877 \\
\hline & & & & & & Firearm & 139 & Suffocation & 847 \\
\hline & & & & & & Poisoning & 23 & Poisoning & 148 \\
\hline
\end{tabular}

Transp = transportation; Nat = natural. * Includes legal intervention and terrorism, but excludes operations of war. 
Table 3. Leading causes of non-fatal injuries among youth aged 0-19 years, National Electronic Injury Surveillance System-All Injury Program, United States, 2015.

\begin{tabular}{|c|c|c|c|c|c|c|c|c|c|}
\hline \multicolumn{2}{|l|}{$<1$ Years } & \multicolumn{2}{|l|}{ 1-4 Years } & \multicolumn{2}{|l|}{ 5-9 Years } & \multicolumn{2}{|l|}{ 10-14 Years } & \multicolumn{2}{|l|}{ 15-19 Years } \\
\hline & Number & & Number & & Number & & Number & & Number \\
\hline Unintentional & 220,498 & Unintentional & $1,761,604$ & Unintentional & $1,598,395$ & Unintentional & $1,865,190$ & Unintentional & $2,235,017$ \\
\hline Fall & 121,531 & Fall & 770,250 & Fall & $\frac{17,362}{617}$ & Fall & $\frac{128,190}{520}$ & Struck By/Against & 493,123 \\
\hline Struck By/Against & 27,829 & Struck By/Against & 295,509 & Struck By/Against & 362,955 & Struck By/Against & 516,099 & Fall & 398,076 \\
\hline Other Bite/Sting & 12,987 & Other Bite/Sting & 157,851 & Other Bite/Sting & 102,571 & Overexertion & 273,389 & Overexertion & 333,062 \\
\hline Foreign Body & 8181 & Foreign Body & 119,900 & Cut/Pierce & 96,322 & Cut/Pierce & 104,152 & MV-Occupant & 261,636 \\
\hline Fire/Burn & 7882 & Cut/Pierce & 73,358 & Overexertion & 79,715 & MV-Occupant & 75,145 & Cut/Pierce & 158,692 \\
\hline Inhal/Suffocation & 7674 & Overexertion & 61,032 & Pedal Cyclist & 61,477 & Pedal Cyclist & 67,167 & Poisoning & 80,971 \\
\hline Cut/Pierce & 5601 & Fire/Burn & 44,985 & MV-Occupant & 61,222 & Other Bite/Sting & 63,771 & Other Bite/Sting & 73,611 \\
\hline Overexertion & 4433 & Dog Bite & 32,425 & Foreign Body & 57,911 & Other Transport & 42,389 & Other Transport & 52,348 \\
\hline Poisoning & 4153 & Poisoning & 30,767 & Dog Bite & 34,955 & Dog Bite & 27,675 & Pedal Cyclist & 50,144 \\
\hline MV-Occupant & 2568 & MV-Occupant & 26,638 & Other Transport & 32,854 & Foreign Body & 22,610 & Fire/Burn & 26,826 \\
\hline Assault-All Causes* & 3299 & Assault-All Causes* & 21,788 & Assault-All Causes* & 22,573 & Assault-All Causes* & 62,606 & Assault-All Causes* & 194,916 \\
\hline Struck By/Against & 2460 & Sexual Assault & 10,333 & Struck By/Against & 13,267 & Struck By/Against & $\overline{49,363}$ & Struck By/Against & 142,628 \\
\hline Poisoning & 189 & Struck By/Against & 8390 & Sexual Assault & 7252 & Sexual Assault & 6735 & Sexual Assault & 15,377 \\
\hline \multirow[t]{5}{*}{ Fall } & 185 & Fire/Burn & 990 & Other Bite/Sting & 760 & Cut/Pierce & 1602 & Cut/Pierce & 12,297 \\
\hline & & & & & & Self-harm-All Causes & 36,737 & Self-harm-All Causes & 92,908 \\
\hline & & & & & & Poisoning & 14,267 & Poisoning & $\overline{42,632}$ \\
\hline & & & & & & Cut/Pierce & 12,799 & Cut/Pierce & 28,087 \\
\hline & & & & & & Struck By/Against & 1849 & Struck By/Against & 3601 \\
\hline
\end{tabular}




\subsection{Trends in Mortality and Morbidity}

\subsubsection{Mortality}

Individuals younger than 1 and 15-19 years of age had the highest unintentional injury death rates between 1999 and 2015 (Figure 1) with the unintentional injury death rate among infants increasing approximately $46 \%$ (22.3 in 1999 to $32.5 \%$ in 2015) and rate among 15-19 age group decreasing $44 \%$ (33.3 in 1999 to 18.6 in 2015). The rates for all other age groups decreased between 37 and $54 \%$. Those aged 1-4, 5-9, and 10-14 years had lower rates each year than infants or those aged 15-19 years. The lowest death rates were found among children aged 5-9 years, ranging from 3.56 to 7.08 over this time period. Notably, the death rates of infants (31.0) surpassed that of adolescents aged 15-19 years (29.4) beginning in 2007.

Homicide death rates also were highest among those $<1$ (ranging from 6.3 to 9.1) and 15-19 (ranging from 6.7 to 10.9) years of age between 1999 and 2015 (Figure 1). Homicide death rates decreased over the 17-year study period for all age groups. Suicide deaths were reported only for the two older age groups. Suicide death rates increased for both age groups between 2007 and 2015, with the increases from 2007 and 2015 being 130\% and 46\% for the 10-14 and 15-19 year olds, respectively (Figure 1).

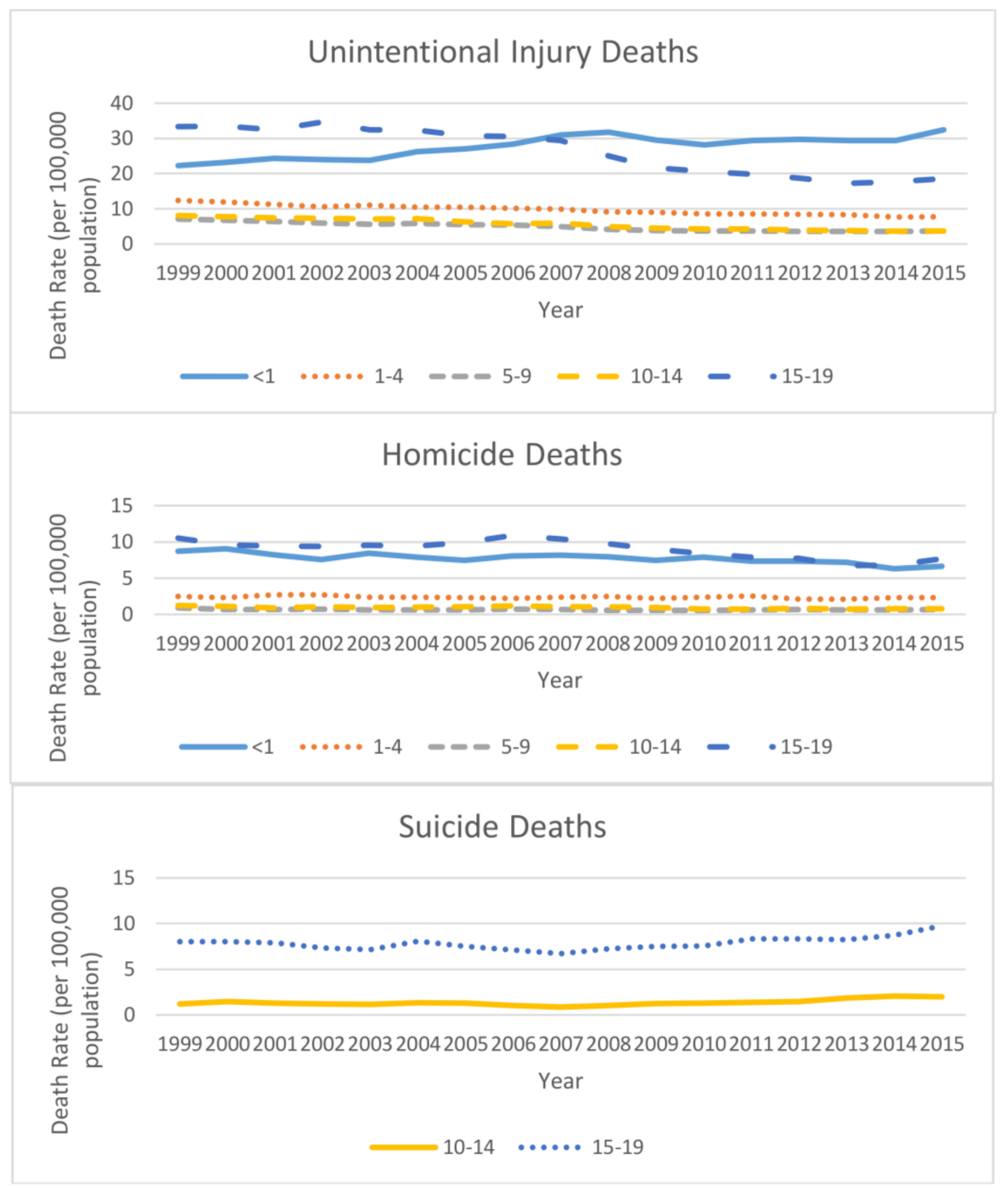

Figure 1. Injury and violence-related death rates (per 100,000 population) among youth aged 0-19 years by intent and age group, National Vital Statistics System, United States, 1999-2015. 


\subsubsection{Morbidity}

Individuals aged 1-4 and 15-19 years had the highest non-fatal unintentional injury rates (Figure 2). The non-fatal unintentional injury rates decreased in all age groups, with the age-adjusted rate for all ages combined decreasing 22.0\% from an estimated 11,988 per 100,000 in 2001 to 9352 in 2015. Non-fatal injury rates for assaults among 15-19 year olds (ranging from 1471 in 2001 to 923 in 2015) were over twice the rates of the other age groups. The non-fatal injury rate for assaults among those aged 0-19 years was estimated to be 712 in 2001 and 372 in 2015, a 47.8\% decrease. Rates for non-fatal self-harm increased by over 130\% among 10-14 year olds (76 in 2001, 178 in 2015), and increased by $47 \%$ among $15-19$ year olds (299 in 2001, 440 in 2015) (Figure 2).

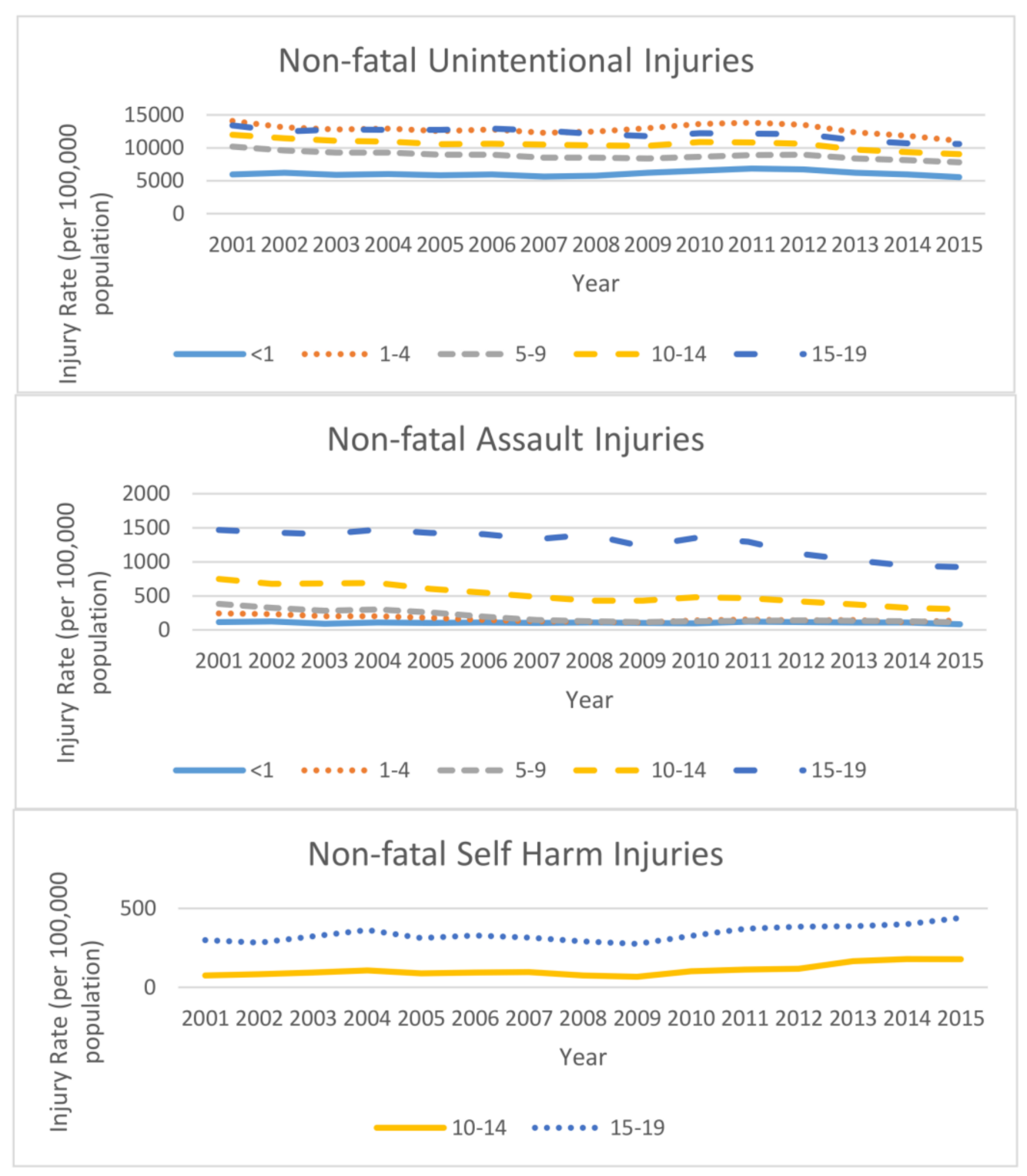

Figure 2. Non-fatal injury rates (per 100,000 population) among youth aged 0-19 years by intent, age group, and year, National Electronic Injury Surveillance System-All Injury Program, United States, 2001-2015. 


\subsection{Injury Mortality by States and Urban Status}

\subsubsection{States}

Age-adjusted death rates (2009-2015 combined) by intent varied greatly across states and regions of the United States (Figure 3). Unintentional injury death rates generally were high in the southeast and low in New England and the Mideast. States with rates in the highest quartile included AL, AK, AR, KY, LA, MO, MS, MT, ND, OK, SC, SD, and WY. Homicide death rates were lowest in New England and states along the western northern border (e.g., ID, MN, MT, ND, OR) of the United States and highest in the middle of the country (e.g., AL, IL, OK, LA, MI, MO, MS, NM, TN). Suicide death rates were high in the Rocky Mountains (e.g., CO, ID, MT, UT, WY) and lower in the Southeast (e.g., GA, FL, MS).
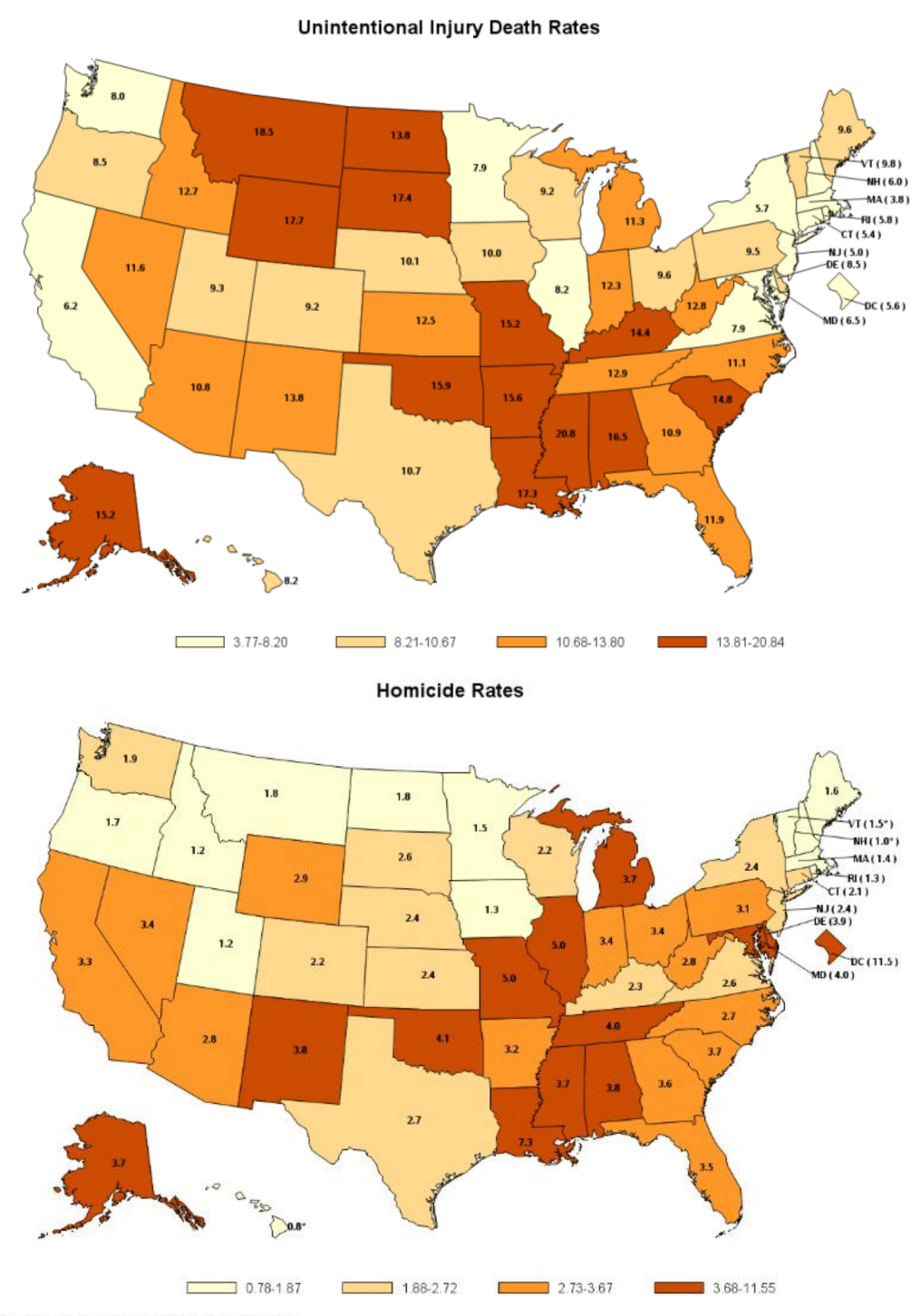

Figure 3. Cont. 


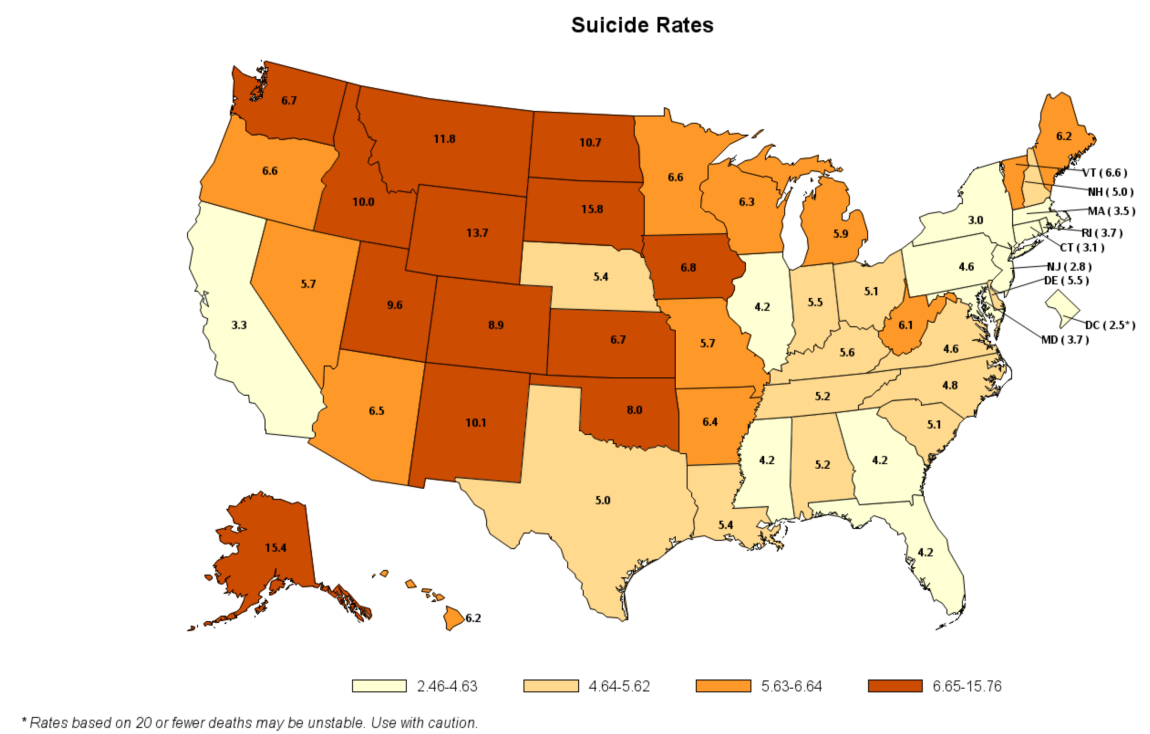

Figure 3. Injury and violence related death rates (per 100,000 population) among youth aged 0-19 years by intent and state, National Vital Statistics System, United States, 2009-2015. Note: data for Suicides is only for 10-19 year olds.

\subsubsection{Urban Status}

Age-adjusted unintentional injury death rates in metro areas were 13.7 in 1999 and 8.5 in 2015, while rates in non-metro areas were 25.9 in 1999 and 16.7 in 2015. Unintentional injury death rates among youth aged 0-19 years in metro areas were $47.3 \%$ lower than non-metro areas in 1999 and 49.2\% lower in 2015. Age-adjusted homicide death rates in metro areas were 4.4 in 1999 and 3.2 in 2015, while rates in non-metro areas were approximately 2.5 in both 1999 and 2015, resulting in a rate decrease of $28.4 \%$ in metro areas from 1999 to 2015 compared with only a $2.0 \%$ decrease in non-metro areas. Homicide rates were $76.5 \%$ higher in metro versus non-metro areas in 1999 versus $28.9 \%$ higher in 2015. Age-adjusted suicide death rates (for 10-19 year olds) in metro areas were 4.3 in 1999 and 5.4 in 2015, while rates in non-metro areas were 6.1 in 1999 and 8.4 in 2015. This resulted in suicide rate increases over this time period of $25.8 \%$ in metro areas and $39.3 \%$ in non-metro areas.

\subsubsection{Race and Ethnicity}

Unintentional injury death rates from 2013-2015 were highest among American Indian and Alaskan Native peoples (AI/AN), with the highest rates among AI/ AN (63.6) and Black (66.8) infants, and AI/AN 15-19 year olds (32.5) (Figure 4). Overall, homicide rates were highest among Blacks (10.1 for all ages combined), with Blacks 15-19 years old having homicide rates over twice (28.8) any other age and race category. Suicide rates were highest among AI/AN (5.7 for all ages combined) in our study population, with AI/AN 15-19 year olds (27.3) having the highest death rates. 

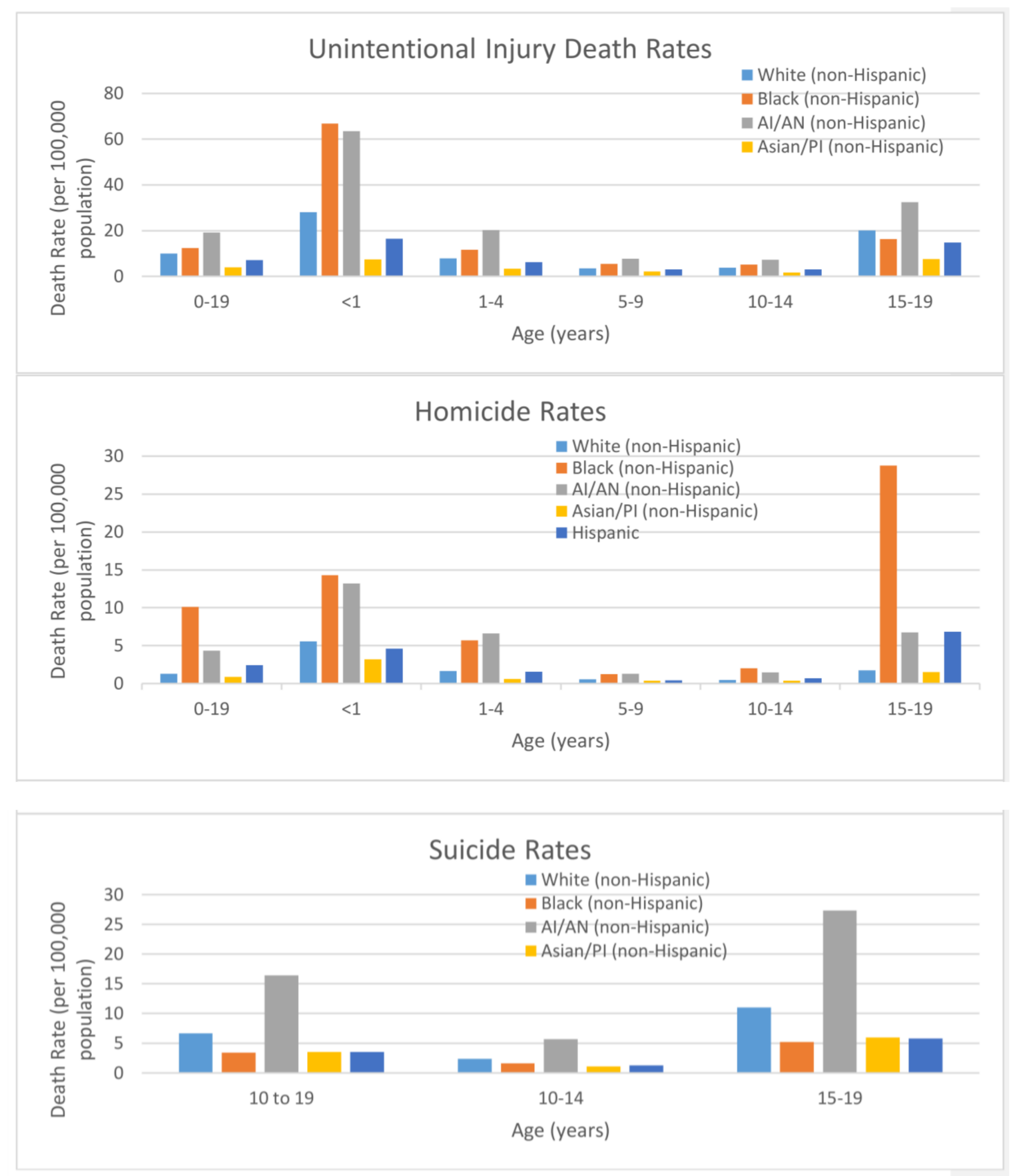

Figure 4. Injury and violence related death rates (per 100,000 population) among youth aged 0-19 years by intent and race, National Vital Statistics System, United States, 2013-2015.

\subsection{Injury Death Rates by Sex, Single Year of Age, Intent, and Mechanism}

The patterns of death rates widely varied when looking at specific injury intents, mechanisms, sex, and year of age as seen in Figure 5 (note that the scales for the vertical axes are different for each intent and mechanism). For example, MV occupant death rates were essentially equal for males and females through the age when adolescents begin to drive on their own; then the male rate is higher than the female rate; unintentional poisonings, homicides, and suicides had a similar age/gender patterns with the divergence between males and females widening with age. For some mechanisms, death rates substantially varied by age. For example, unintentional suffocation death rates were essentially zero 
for individuals older than 12 months, unintentional drowning and fire/burn death rates peaked for children at 1-4 years old. Some death rates for specific mechanisms and intents were very low, including unintentional poisonings among those less than 15 , unintentional falls among 7-12 year olds, unintentional suffocations for all older than 12 months, and homicides among 7-13 year olds.

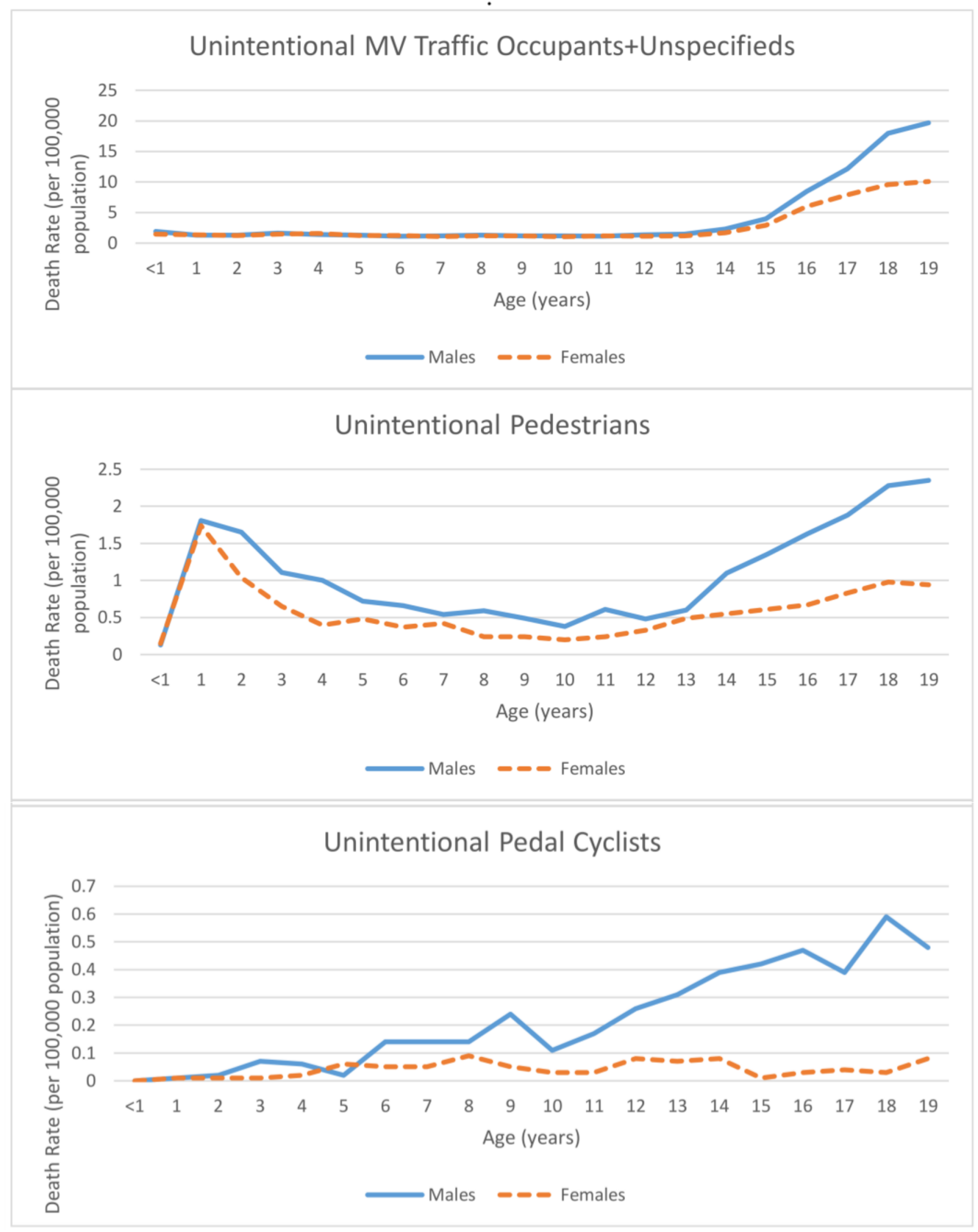

Figure 5. Cont. 


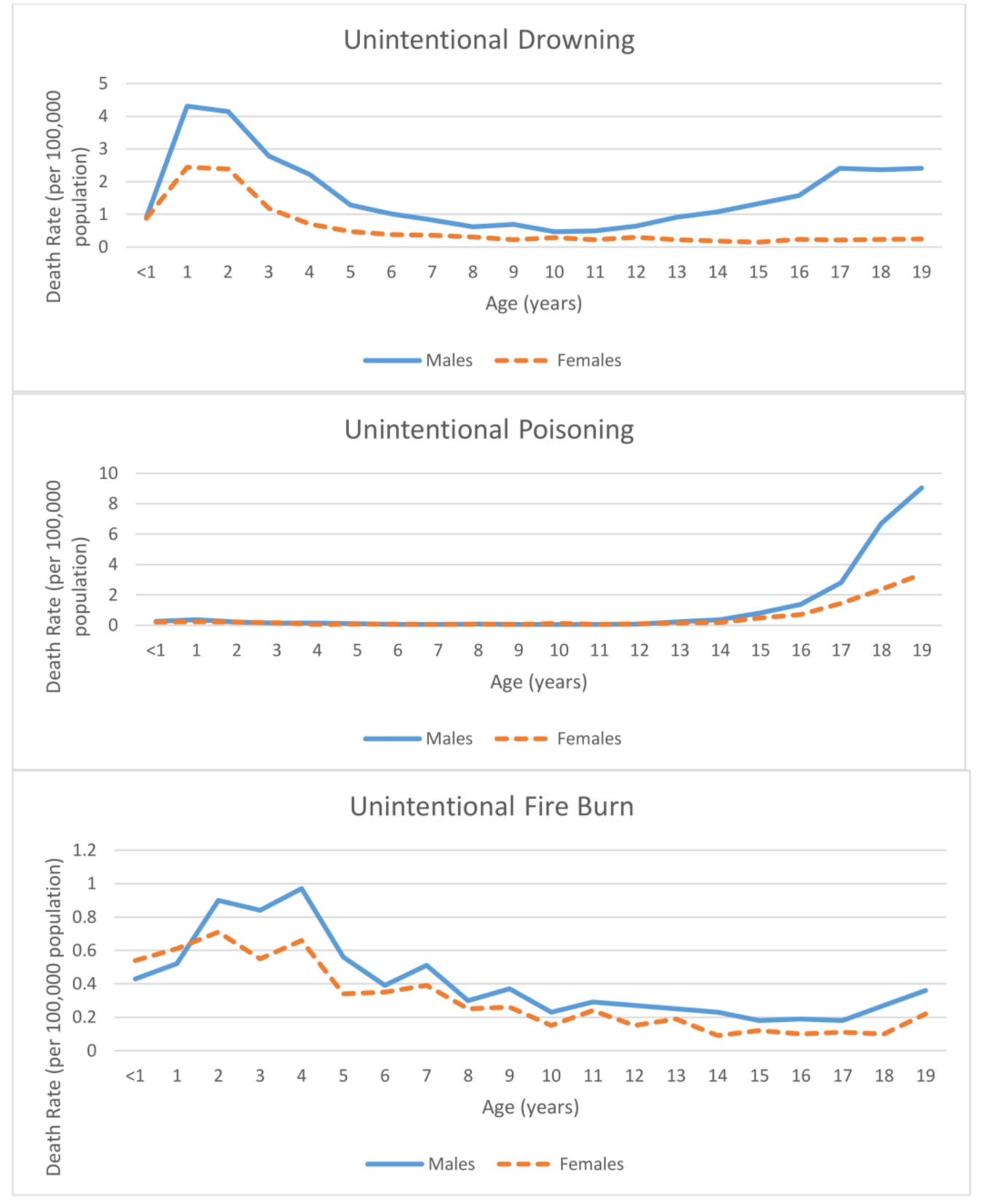

Figure 5. Cont. 


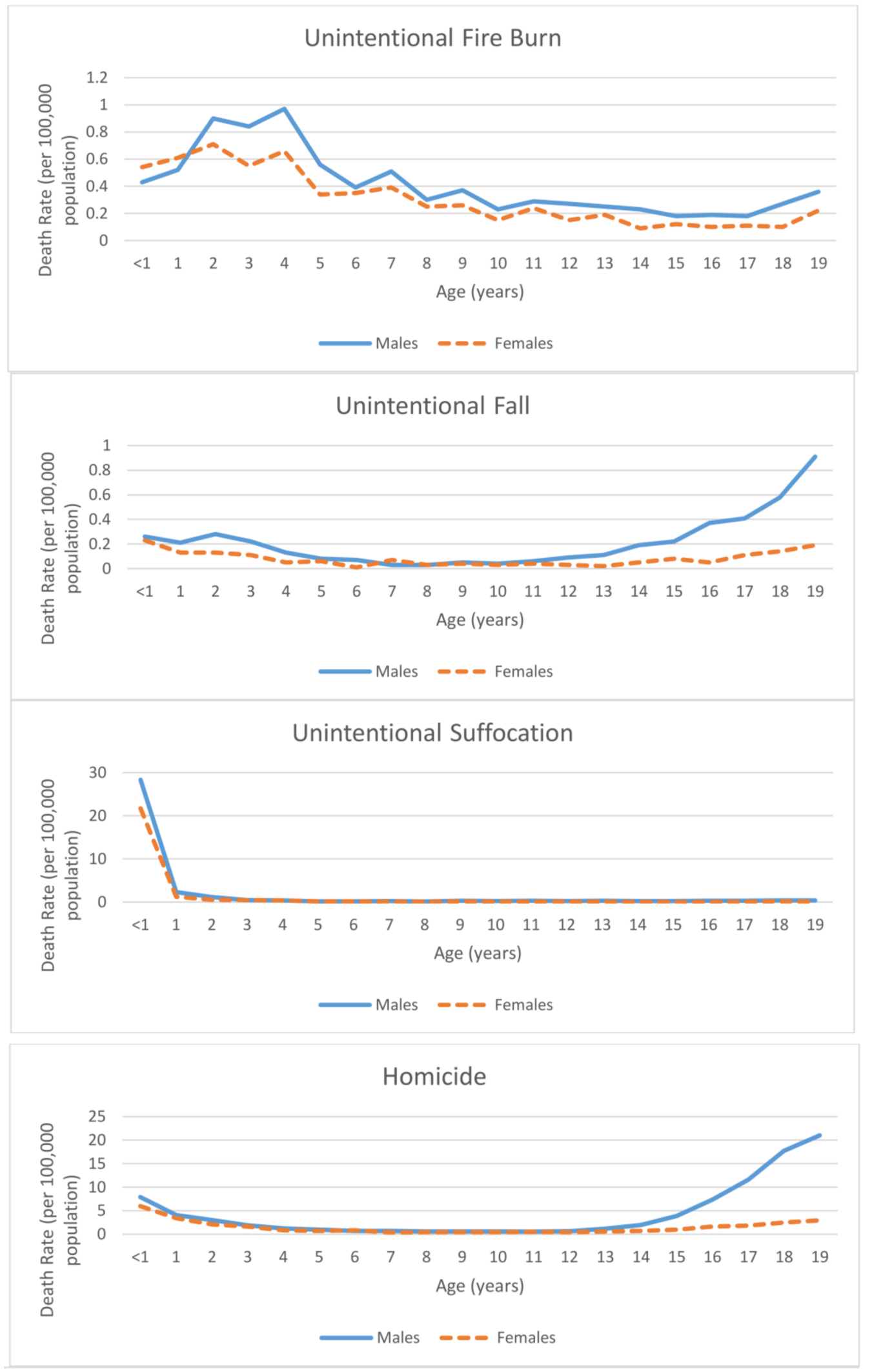

Figure 5. Cont. 


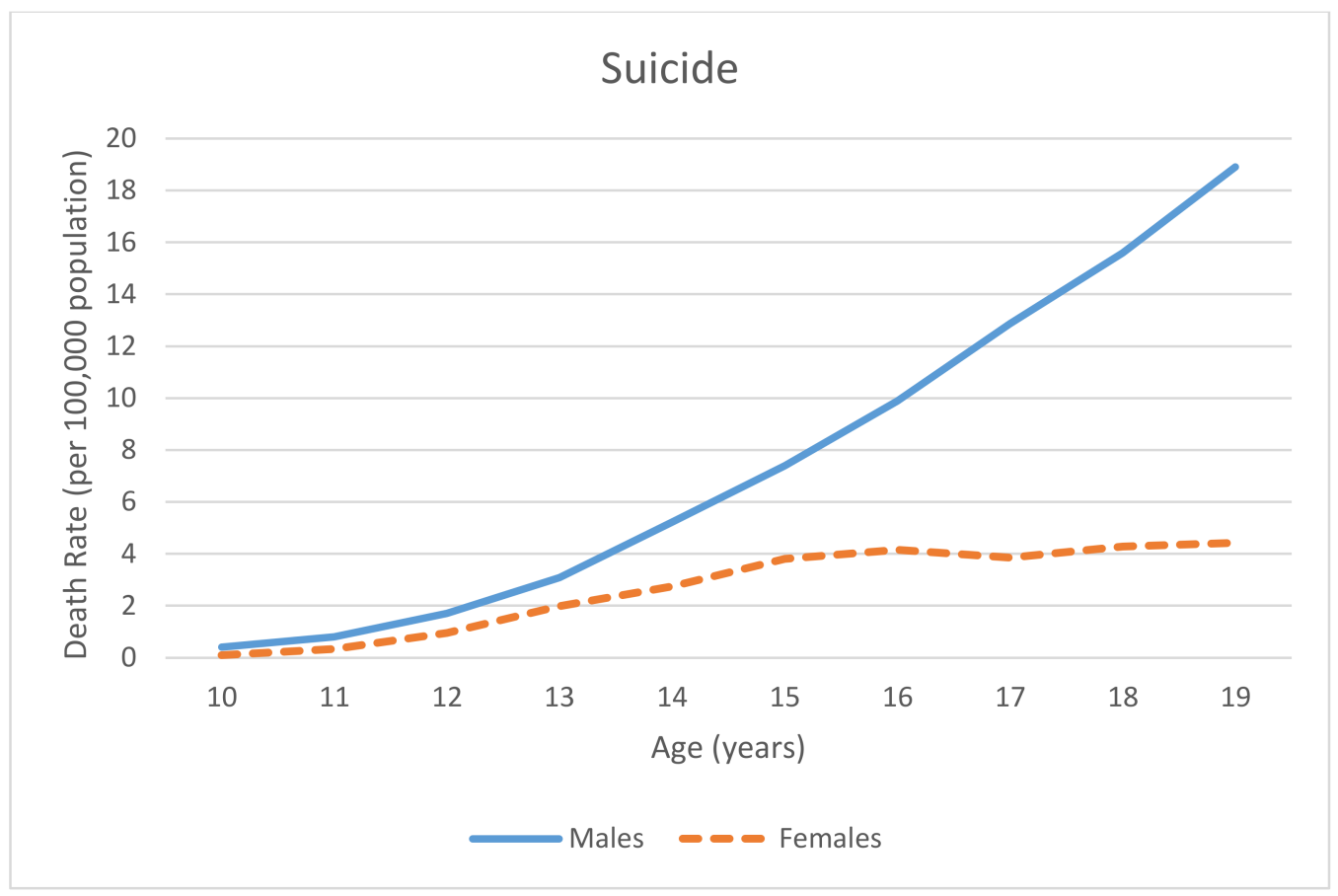

Figure 5. Injury and violence related death rates (per 100,000 population) among youth (ages 0-19 years) by intent, mechanism, and age group, National Vital Statistics System, United States, 2011-2015. Note: The scales for the vertical axes are different for each intent and mechanism.

\section{Discussion}

Several published studies have examined the epidemiology of fatal and non-fatal injuries among U.S. children and adolescents [2,8-12]. Our study complements previous work by using the more recent data, and presenting information on injuries from all intents (i.e., unintentional, homicide/assaults, and suicide/self-harm). The results indicate several major areas of concern, most notably the rising death rates among certain age groups for unintentional injuries and for suicide.

As expected, the most common causes of injury death varied by age group. Infants were at most risk for suffocations, while those 1-4 years of age were at highest risk for drowning, homicides, and MV traffic. The top three leading causes of death by age group are: ages 5-9 years, MV traffic, homicide, and drowning; ages 10-14 years, MV traffic, suicide, and homicide; and ages 15-19 years, MV traffic, suicide, and homicide. Our findings are consistent with other studies that suggest there is a relationship between the developmental stage of children and the injuries they sustain $[13,14]$. To be most effective, prevention strategies and programs should be appropriate for the developmental stage of their target audience [15].

Injuries by race/ethnicity showed important disparities, with all unintentional injuries ages 0-19 years showing the lowest rates among Asian/Pacific Islander and the highest rates among Blacks. These rates from 2013-2015 were patterned similarly when viewed by five-year age groups. The striking deaths rates for Blacks under age 1 and 15-19-year old AI/AN youth may be related to the contexts in which these children live, including limited access to resources, environmental factors, disparities in mental and physical health care access and utilization, and high rates of poverty [16]. High rates of homicide among Black youth ages 0-19 years old may reflect disproportionate exposure to social and environmental risk factors for violence- such as poverty, racism, and neighborhood crime - as well as limited educational and occupational opportunities [17-19]. High suicide rates among AI/AN may reflect social and environmental circumstances, including discrimination and historical trauma, exposure to suicides of others, and limited access to health and mental health services (Figure 4) [20]. 
In addition to differences by age and race/ethnicity, we found that the leading causes of injury morbidity and mortality also greatly differed by sex. These results are consistent with previous child injury epidemiology conducted by the CDC [21]. Some of these differences can be attributed to societal expectations, exposure to risks, and behavioral risk factors of the injured child. Injury risk is influenced by a child's temperament (i.e., activity level, impulsivity, and inhibitory control), personality (i.e., sensation seeking), psychosocial and cognitive development (e.g., ability to appraise the risk of a situation, estimation of one's own physical ability) [22]. Additionally, research suggests that for young children, supervision by parents and caregivers can also affect risk for unintentional injury [23]. Supervision can be a powerful protective factor to prevent unintentional injuries, especially for infants and toddlers. Dimensions of supervision include attention (e.g., engagement and interaction with child), proximity (e.g., physical closeness, touching, within reach), and continuity (e.g., continuous, intermittent, or absent) [24].

The field of violence prevention has learned a great deal about which programs, policies, and practices are effective at reducing violence or key risk factors for violence. To help states and communities make decisions about prevention options, the CDC has released a series of technical packages that describe the best available evidence. The technical packages cover suicide, child abuse and neglect (data not specifically presented in this analysis), youth violence, sexual violence, teen dating violence, and intimate partner violence prevention [25-29]. The strategies span the social ecology to reduce risk and enhance protection at the individual, relationship, community, and societal levels. Strategies aim to support safe, stable, nurturing relationships and environments by ensuring a strong start through early childhood education, teaching problem solving and relationship skills, promoting social norms that protect against violence, engaging influential adults and peers, creating protective environments, strengthening economic and other supports to families, and providing support to lessen harms and prevent future risk.

In unintentional injury prevention, implementing effective prevention strategies, such as using seat belts and child safety seats; disposing of unused, unneeded, or expired prescription drugs; wearing bicycle and motorcycle helmets; installing residential smoke alarms; reducing the use of alcohol (data not specifically presented in this analysis); using life jackets; installing four-sided self-latching pool fencing; strengthening graduated driver licensing laws; using safety equipment and implementing injury prevention strategies in sports (data not specifically presented in this analysis); and protecting young workers from injuries on the job will all contribute to reducing unintentional injuries. The CDC National Action Plan for Child Injury Prevention, developed by CDC and more than 60 stakeholder organizations to spark coordinated action to prevent unintentional injuries to children and youth [30], provides a roadmap for strengthening the collection and interpretation of data and surveillance, promoting research, enhancing communications, improving education and training, advancing health systems and health care, and strengthening policy.

To address the prevention of motor vehicle crash injuries, the leading cause of unintentional injury deaths among those aged 5-19 years, the World Health Organization, in collaboration with global partners including CDC, has produced a technical package on traffic injury prevention. The Save LIVES: A Road Safety Technical Package [31] is an evidence-based inventory of priority interventions with a focus on speed management, leadership, infrastructure design and improvement, vehicle safety standards, enforcement of traffic laws, and post-crash survival. The package prioritizes these 6 strategies and details 22 interventions addressing key risk factors, as well as providing guidance on their implementation to save lives on the road. This road safety policy package can help guide decision makers on reducing motor vehicle injuries among children and youth. WHO also produced a World Report on Child Injury Prevention [32], which is a roadmap to keep kids safe by promoting evidence-based injury prevention interventions across all unintentional injury types, with a focus on the five most important causes of unintentional injury—road traffic injuries, drowning, burns, falls, and poisoning - and includes seven recommendations for action. This analysis presents the U.S. burden for these main causes. 
Our study is subject to several limitations. First, it was not possible to examine injury deaths by state and by year, because the low number of deaths in some states would have resulted the need to suppress results to protect the privacy of decedents. Therefore, we used the most recent seven-year data window to show some state differences. Examining deaths at the county-level, which could better inform local decisions on prevention, would pose similar challenges. Second, some death rates presented in this paper are considered unstable because based on a small number of deaths. Third, NEISS-AIP data only include individuals who are seen in an emergency department, so injuries treated in doctors' office, in urgent care centers, or left untreated are not included. For example, many young people are victims of violence, but are not treated in emergency departments. Injury is one aspect of the burden of violence, but it is important to remember that many incidents of violence, such as bullying, neglect, and dating violence or sexual abuse may not result in physical injuries, but can have significant and lasting negative consequences for victims. Fourth, NEISS-AIP is designed to give only national estimates, so state-level analyses were not possible. Fourth, information on race and ethnicity are not collected consistently in the NEISS-AIP because data are from medical records from emergency departments. Fifth, we did not present national estimates using the NEISS-AIP by injury cause, intent, and single year of age, because most of these rates were unstable due to small case counts. Lastly, the data used here may underreport races other than white and black, and underreport Hispanic origin [33].

\section{Conclusions}

Almost 13,000 children and adolescents died in 2015 from unintentional or violence-related injury. This is a substantially smaller number than the 17,500 people who died in 1999 [1] from injuries or violence, an indication that childhood injury prevention efforts are succeeding; however, the rising death rates among certain age groups, races, and in specific geographical locations for unintentional injuries, homicide, and suicide is a concern.

Our results indicate that, in an effort to reduce violence and unintentional injuries to children, it is important to consider cause, intent, age, gender, race, and regional factors to assure that prevention resources are directed to those at greatest risk. Prevention opportunities extend beyond addressing individual risk behaviors to include programs, policies, and strategies that enhance protective factors within the family, schools, neighborhood, and community. The frequency, severity, and potential for death and disability of these injuries together with the high success potential for prevention, make injury prevention a key public health goal to improve child and adolescent health in the future.

Author Contributions: Michael F. Ballesteros conceptualized the ideas for this research, contributed to the analysis, and wrote the manuscript. Dionne D. Williams conducted the analysis and reviewed the document. Karin A. Mack conceptualized the ideas for this research, reviewed the document, and wrote the manuscript. Thomas R. Simon and David A. Sleet reviewed the document and wrote the manuscript.

Disclaimer: The findings and conclusions in this manuscript are those of the author(s) and do not necessarily represent the official position of the Centers for Disease Control and Prevention.

Conflicts of Interest: The authors declare no conflict of interest.

\section{References}

1. Centers for Disease Control and Prevention. Web-Based Injury Statistics Query and Reporting System (WISQARS). Available online: https:/ / www.cdc.gov/injury/wisqars/ (accessed on 9 August 2017).

2. Dellinger, A.M.; Gilchrist, J. Leading Causes of Fatal and Nonfatal Unintentional Injury for Children and Teens and the Role of Lifestyle Clinicians. Am. J. Lifestyle Med. 2017. [CrossRef]

3. Ballesteros, M.F.; Webb, K.; McClure, R.J. A review of CDC's Web-based Injury Statistics Query and Reporting System (WISQARS): Planning for the future of injury surveillance. J. Saf. Res. 2017, 61, 211-215. [CrossRef] [PubMed]

4. Centers for Disease Control and Prevention. Tools for Categorizing Injuries Using ICD Codes. Available online: https:/ / www.cdc.gov/nchs/injury/injury_tools.htm (accessed on 1 July 2017). 
5. Ballesteros, M. Motor vehicle occupant mortality coding: Comparison of NVSS and FARS. In Proceedings of the SAVIR 2017 Conference: Innovations in Injury Prevention Science, Ann Arbor, MI, USA, 18-20 September 2017.

6. Centers for Disease Control and Prevention. NCHS Urban-Rural Classification Scheme for Counties. Available online: https://www.cdc.gov/nchs/data_access/urban_rural.htm (accessed on 1 July 2017).

7. Centers for Disease Control and Prevention. U.S. Census Populations with Bridged Race Categories. Available online: https://www.cdc.gov/nchs/nvss/bridged_race.htm (accessed on 1 July 2017).

8. Sleet, D.A.; Ballesteros, M.F.; Borse, N.N. A review of unintentional injuries in adolescents. Annu. Rev. Public Health 2010, 31, 195-212. [CrossRef] [PubMed]

9. Bennett, M.D., Jr.; Hall, J.; Frazier, L., Jr.; Patel, N.; Barker, L.; Shaw, K. Homicide of children aged 0-4 years, 2003-04: Results from the National Violent Death Reporting System. Inj. Prev. 2006, 12 (Suppl. 2), ii39-ii43. [CrossRef] [PubMed]

10. Klevens, J.; Leeb, R.T. Child maltreatment fatalities in children under 5: Findings from the National Violence Death Reporting System. Child Abuse Negl. 2010, 34, 262-266. [CrossRef] [PubMed]

11. Centers for Disease Control and Prevention. Variation in homicide risk during infancy-United States, 1989-1998. Morb. Mortal. Wkly. Rep. 2002, 51, 187-189.

12. Sullivan, E.M.; Annest, J.L.; Simon, T.R.; Luo, F.; Dahlberg, L.L.; Centers for Disease Control and Prevention. Suicide trends among persons aged 10-24 years-United States, 1994-2012. Morb. Mortal. Wkly. Rep. 2015, 64, 201-205.

13. Flavin, M.P.; Dostaler, S.M.; Simpson, K.; Brison, R.J.; Pickett, W. Stages of development and injury patterns in the early years: A population-based analysis. BMC Public Health 2006, 6, 187. [CrossRef] [PubMed]

14. MacInnes, K.; Stone, D.H. Stages of development and injury: An epidemiological survey of young children presenting to an emergency department. BMC Public Health 2008, 8, 120. [CrossRef] [PubMed]

15. Mercy, J.A.; Sleet, D.A.; Doll, L.S. Applying a developmental approach to injury prevention. Am. J. Health Educ. 2003, 34, S-6-S-12. [CrossRef]

16. Drake, B.; Rank, M.R. The racial divide among American children in poverty: Reassessing the importance of neighborhood. Child. Youth Serv. Rev. 2009, 31, 1264-1271. [CrossRef]

17. Sampson, R.J.; Morenoff, J.D.; Raudenbush, S. Social anatomy of racial and ethnic disparities in violence. Am. J. Public Health 2005, 95, 224-232. [CrossRef] [PubMed]

18. Sharkey, P.; Sampson, R.J. Violence, cognition, and neighborhood inequality in America. Soc. Neurosci. Brain Mind Soc. 2015, 660, 320-339.

19. Zimmerman, G.M.; Messner, S.F. Individual, family background, and contextual explanations of racial and ethnic disparities in youths' exposure to violence. Am. J. Public Health 2013, 103, 435-442. [CrossRef] [PubMed]

20. Office of the Surgeon General. Publications and reports of the surgeon general. In 2012 National Strategy for Suicide Prevention: Goals and Objectives for Action; A Report of the U.S. Surgeon General and of the National Action Alliance for Suicide Prevention; US Department of Health \& Human Services (US): Washington, DC, USA, 2012.

21. Borse, N.N.; Gilchrist, J.; Dellinger, A.M.; Rudd, R.A.; Ballesteros, M.F.; Sleet, D.A. CDC Childhood Injury Report: Patterns of Unintentional Injuries among 0-19 Years Olds in the United States, 2000-2006; Centers for Disease Control and Prevention: Atlanta, GA, USA, 2008.

22. Schwebel, D.C.; Gaines, J. Pediatric unintentional injury: Behavioral risk factors and implications for prevention. J. Dev. Behav. Pediatr. 2007, 28, 245-254. [CrossRef] [PubMed]

23. Petrass, L.; Blitvich, J.D.; Finch, C.F. Parent/Caregiver supervision and child injury: A systematic review of critical dimensions for understanding this relationship. Fam. Community Health 2009, 32, 123-135. [CrossRef] [PubMed]

24. Saluja, G.; Brenner, R.; Morrongiello, B.A.; Haynie, D.; Rivera, M.; Cheng, T.L. The role of supervision in child injury risk: Definition, conceptual and measurement issues. Inj. Control Saf. Promot. 2004, 11, 17-22. [CrossRef] [PubMed]

25. Basile, K.C.; DeGue, S.; Jones, K.; Freire, K.; Dills, J.; Smith, S.G.; Raiford, J.L. STOP SV: A Technical Package to Prevent Sexual Violence; National Center for Injury Prevention and Control, Centers for Disease Control and Prevention: Atlanta, GA, USA, 2016. 
26. David-Ferdon, C.; Vivolo-Kantor, A.M.; Dahlberg, L.L.; Marshall, K.J.; Rainford, N.; Hall, J.E. A Comprehensive Technical Package for the Prevention of Youth Violence and Associated Risk Behaviors; National Center for Injury Prevention and Control, Centers for Disease Control and Prevention: Atlanta, GA, USA, 2016.

27. Fortson, B.L.; Klevens, J.; Merrick, M.T.; Gilbert, L.K.; Alexander, S.P. Preventing Child Abuse and Neglect: A Technical Package for Policy, Norm, and Programmatic Activities; National Center for Injury Prevention and Control, Centers for Disease Control and Prevention: Atlanta, GA, USA, 2016.

28. Niolon, P.H.; Kearns, M.C.; Dills, J.; Rambo, K.; Irving, S.M.; Armstead, T.L.; Gilbert, L.K. Preventing Intimate Partner Violence across the Lifespan: A Technical Package of Programs, Policies, and Practices; National Center for Injury Prevention and Control, Centers for Disease Control and Prevention: Atlanta, GA, USA, 2017.

29. Stone, D.M.; Holland, K.M.; Bartholow, B.N.; Crosby, A.E.; Davis, S.P.; Wilkins, N. Preventing Suicide: A Technical Package of Policies, Programs, and Practice; National Center for Injury Prevention and Control, Centers for Disease Control and Prevention: Atlanta, GA, USA, 2017.

30. Centers for Disease Control and Prevention. National Action Plan for Child Injury Prevention; National Center for Injury Prevention and Control, Centers for Disease Control and Prevention: Atlanta, GA, USA, 2012.

31. World Health Organization. Save LIVES: A Road Safety Technical Package; WHO: Geneva, Switzerland, 2017.

32. World Health Organization. World Report on Child Injury Prevention; WHO: Geneva, Switzerland, 2008.

33. Centers for Disease Control and Prevention. The Validity of Race and Hispanic-Origin Reporting on Death Certificates in the United States: An Update 2016. Available online: https:/ /www.cdc.gov/nchs/data/ series/sr_02/sr02_172.pdf (accessed on 1 March 2018).

(C) 2018 by the authors. Licensee MDPI, Basel, Switzerland. This article is an open access article distributed under the terms and conditions of the Creative Commons Attribution (CC BY) license (http://creativecommons.org/licenses/by/4.0/). 